\title{
Seasonal and daily cycles of stem radial variation of Pinus pinaster in a drought-prone environment
}

\author{
Joana Vieira $^{\mathrm{a}, *}$, Sergio Rossi ${ }^{\mathrm{b}}$, Filipe Campelo $^{\mathrm{a}}$, Helena Freitas $^{\mathrm{a}}$, Cristina Nabais $^{\mathrm{a}}$ \\ ${ }^{a}$ CFE - Centro de Ecologia Funcional, Departamento de Ciências da Vida, Faculdade de Ciências e Tecnologia, Universidade de Coimbra, Coimbra, Portugal

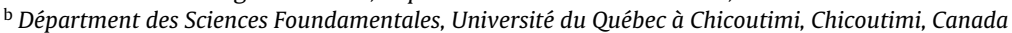

\section{A R T I C L E I N F O}

\section{Article history:}

Received 4 January 2013

Received in revised form 16 April 2013

Accepted 11 June 2013

\section{Keywords:}

Automatic dendrometer

Tree water deficit

Pinus pinaster

Mediterranean

Water relations

Summer quiescence

\begin{abstract}
A B S T R A C T
High resolution measurements of stem diameter variation can provide valuable information on the growth process as well as the tree water status. This study investigates the hourly variations in stem radial increment of maritime pine growing on the west coast of Portugal, under a Mediterranean climate with a pronounced summer drought. We tested the hypotheses that (1) stem radius variation in maritime pine has a daily and seasonal pattern that reflects the availability of water and (2) that once the internal water storage is depleted the tree enters a quiescent state. During 2010, stem radius variations were monitored in four similar trees with automatic dendrometers. Tree water deficit was extracted from the stem radial variation. The stem cycle approach was used to divide the daily cycles into contraction, recovery and increment phases. The seasonal cycle was divided into five periods: winter dormancy, spring growth, pre-summer contraction, summer quiescence and autumn re-hydration. Amplitude and duration of each phase were calculated for each cycle and correlated with precipitation, maximum and minimum temperature. Continuous positive radial increment started in spring and reached its maximum by the end of June. A shrinking period was observed in summer, with amplitudes of contraction and recovery 10 times higher than in the other periods. The inability of the trees to recover from the water lost due to transpiration was responsible for stem shrinking and quiescence observed during summer. In autumn, a period of re-hydration and rapid expansion was observed after precipitation, restoring the tree to a physiologically active state. Daily variations in stem radius of maritime pine were mainly determined by the course of transpiration and thus dependent on temperature and tree water status.
\end{abstract}

(c) 2013 Elsevier B.V. All rights reserved.

\section{Introduction}

The variation in stem size of trees results from an irreversible component due to growth and a reversible component due to changes in the water balance of tissues (Irvine and Grace, 1997). As a general rule, the stem contracts during the day, due to transpiration and photosynthesis and expands during the night and on rainy days when water reserves are gradually replenished. Cermak et al. (2007) observed that the internal water storage can provide a significant proportion of the total diurnal and even seasonal water used by a plant. The water stored in the elastic tissues of the stem buffers the lag between roots and shoot, thus preventing embolisms and ensuring optimal transpiration rates (Peramaki et al., 2005). The dynamics of the daily changes in stem size can thus provide

\footnotetext{
* Corresponding author at: CFE - Centro de Ecologia Funcional, Departamento de Ciências da Vida, Faculdade de Ciências e Tecnologia, Universidade de Coimbra, Apartado 3046, 3001-401 Coimbra, Portugal. Tel.: +351 239855210; fax: +351239855211.

E-mail address: joana.vieira@uc.pt (J. Vieira).
}

valuable information about the water status and radial growth of trees (Deslauriers et al., 2003, 2007; Downes et al., 1999; Turcotte et al., 2009; Zweifel et al., 2000). Infact, stem radial variation can be de-trended in order to extract the tree water deficit, (Drew et al., 2011; Zweifel et al., 2005).

It is well established that timing and magnitude of daily variations in stem size are mainly determined by the course of transpiration and soil water content (Kozlowski, 1976; Zweifel et al., 2006). So, it is expected that these daily cycles are strictly dependent on microclimatic conditions and can quickly change according to weather conditions. Dendrometer data collected in the Swiss Alps by King et al. (2012) demonstrated that the amplitude and duration of the circadian cycles of Norway spruce (Picea abies Karst.) and European larch (Larix decidua Mill.) changed during the year. Smaller cycles were observed on rainy days and larger ones when the daily mean temperature was between 15 and $20^{\circ} \mathrm{C}$. Duchesne and Houle (2011) studied the daily variation in stem radius of balsam fir [Abies balsamea (L) Mill.] growing in the boreal forest of Quebec and observed that stem expansion was higher on rainy days. In the Italian Alps, an eight year study on the stem radial variation of timberline conifers found that stem 
increment responded positively to precipitation and negatively to temperature (Deslauriers et al., 2007). All the above-mentioned studies were performed in cold environments with a short growing season, where water availability is not generally a problem. Are the daily and seasonal changes of stem diameter the same in a drought prone environment, with a longer growing season, like the Mediterranean climate? If not, how do trees respond to water stress?

Seasonal variations in stem radius have already been studied in the Mediterranean region with contradictory findings. Gutierrez et al. (2011) reported that Quercus ilex L. radial increment was mainly constrained by temperature, whereas Camarero et al. (2010) observed that in Juniperus thurifera L. and Pinus halepensis (Miller) the climatic response changed during the year, with stem radius variations dependent on temperature during growth onset and on precipitation during the summer. A different study revealed that Abies pinsapo (Boiss.) wood formation was greatly reduced by drought (Linares et al., 2009). Although radial increment has already been studied on a seasonal level, the daily variations of stem radius still remain undetermined under a Mediterranean climate. In this study we describe the seasonal and daily variations in the stem radius of maritime pine (Pinus pinaster Ait.), growing on a drought prone site in Portugal. We tested the hypotheses that (1) changes in stem size have a seasonal and daily pattern that reflects the availability of water and (2) once the internal water storage is depleted the tree enters a quiescent state.

\section{Methods}

\subsection{Study site}

The study was conducted in Perimetro Florestal Dunas de Cantanhede $\left(40^{\circ} 21^{\prime} 35.15^{\prime \prime} \mathrm{N}, 8^{\circ} 49^{\prime} 10.06^{\prime \prime} \mathrm{W} ; 15\right.$ m.a.s.l.) on the west coast of Portugal. The study site is a forest plantation of maritime pine, characterized by dominant and co-dominant trees with an average age of 45 years and a stand density of about 230 trees ha ${ }^{-1}$. The climate is typically Mediterranean with oceanic influence, precipitation occurring mainly in autumn and winter and a pronounced summer drought. Historical data for the period 1979-2009 reported an annual mean temperature and total precipitation of $16.2^{\circ} \mathrm{C}$ and $942 \mathrm{~mm}$, respectively (CRU).

\subsection{Data collection}

From January to November 2010, automatic band dendrometers (EcoMatik, model DC, Munich, Germany) were used to measure stem perimeter variations in four trees with similar characteristics in terms of dominance, vigor and growth of the previous 15 years. The dendrometers were installed on the stem at a height of about $3 \mathrm{~m}, 1$ month before the start of the growing season, to allow a period of adjustment. Before installing the dendrometers, the outermost tissues of the bark were removed to reduce the influence of hygroscopic swelling and shrinkage of the bark, and to ensure a close contact with the xylem. Plastic beads were placed around the dendrometer cable to reduce friction with the tree bark. The dendrometer sensors were linear variable differential transducers with an accuracy of $7 \mu$ m enclosed in an aluminum frame and attached to the tree via a stainless-steel cable. Sensors and cables have a thermal expansion coefficient inferior to 0.1 and $1.4 \times 10^{-6} \mu \mathrm{m} \mathrm{C}^{-1}$, respectively. Measurements were collected every $20 \mathrm{~min}$ and stored in a datalogger (The ulogger $4 \mathrm{R}$, EcoMatik, Munich, Germany). Data were transformed into radial measurements by dividing the circumference by $2 \pi$, and hourly averages were calculated for the following analyses. The final dendrometer series presented missing data due to technical problems that occurred during the monitoring and outlier values that were removed.

Daily maximum and minimum temperatures and total precipitations were acquired from the nearest meteorological station belonging to the Instituto Português de Meteorologia and located in Figueira da Foz, at $25 \mathrm{~km}$ from the study site.

\subsection{Extraction of stem variation phases}

The time series obtained from each tree were individually processed according to the stem cycle approach of Downes et al. (1999), modified by Deslauriers et al. (2003). Cycle extraction was performed using a three-step procedure composed of two SAS routines (SAS Institute, Inc.) specially developed to analyze hourly automatic dendrometer data (Deslauriers et al., 2011). The procedure divides the series into three distinct phases: (1) contraction, the period between the first maximum radius and the next minimum; (2) recovery, the period from the minimum until the position of the previous maximum value or when the stem reverts to a contraction phase; and (3) radial increment, which can be positive or negative depending on whether or not the previous maximum was achieved (Fig. 1). A cycle was constituted by a contraction, followed by a recovery and a radial increment phase, when present. For each cycle, the SAS routines calculated the amount of stem radial variation and its relative duration.

In order to better describe stem radial variation over the year, the dendrometer series were divided into five periods according to the amplitude of the cycles and net radius variation (Turcotte et al., 2009): period 1, winter dormancy during which the radius variation was around zero [Day of the Year (DOY) 20-77]; period 2 , spring growth, from the start of positive radius increment (when the daily increment was higher than in the previous day), until the spring maximum (DOY 78-178); period 3, pre-summer contraction, when the daily increment was negative (DOY 179-214); period 4, summer dormancy, when the amplitude of the cycles reached minimum values (DOY 215-275); and period 5, autumn re-hydration, during which the radial increment increased rapidly in a short period of time (DOY 276-328). Stem radial variation was also averaged per hour in order to compare its daily amplitude in the five periods.

\subsection{Tree water deficit}

To distinguish changes in stem radius due to water content variability and growth, a de-trending approach was used as described in Zweifel et al. (2005). Tree water deficit $(\Delta W)$ was calculated as the difference in stem size under increasingly dry conditions relative to the size of the fully hydrated stem (Fig. 2). We assumed that at the beginning of the study the stem was fully hydrated, thus presenting a zero value of $\Delta W$. Increasingly negative values indicate increasing tree water deficit.

\subsection{Statistical analyses}

The three phases of stem radial variation were re-scaled at an average of zero (by subtracting the mean from each value) and linear regressions were calculated between amplitude and duration of each phase. Maximum and minimum temperatures and total precipitation were calculated for each circadian cycle and compared with the corresponding radial variations. Pearson correlations were performed separately for the five periods to determine the influence of weather on the amount of stem variation and duration of each phase.

Missing data and the different lengths of the selected periods could affect the robustness of statistical tests. To address this 


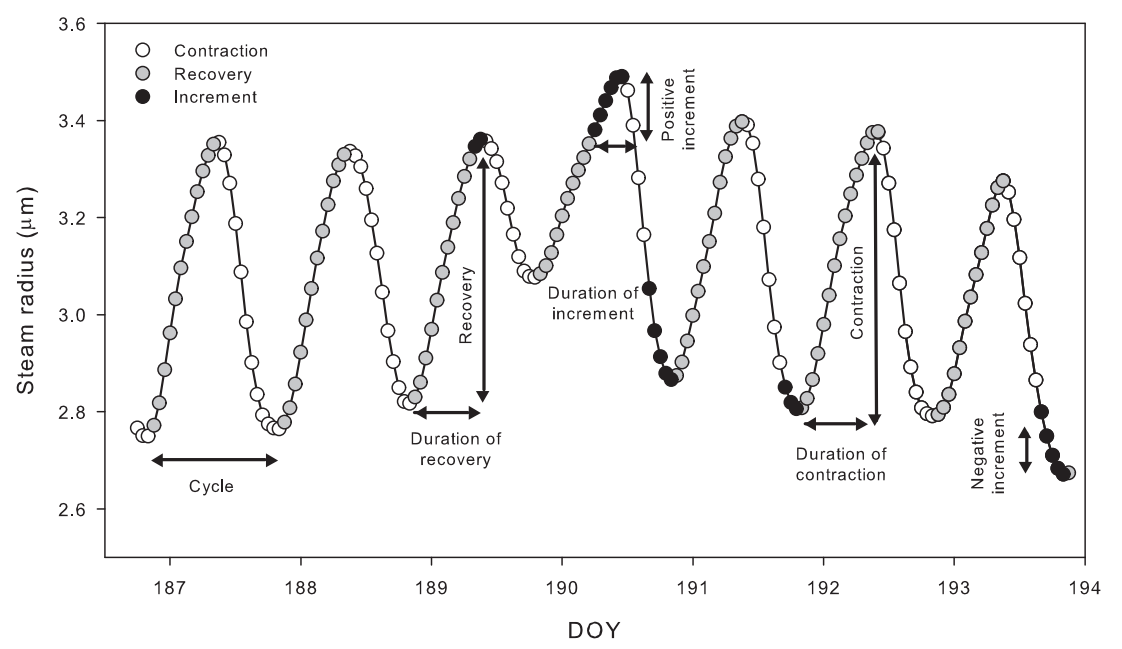

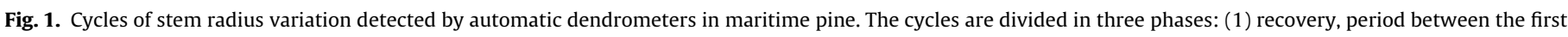

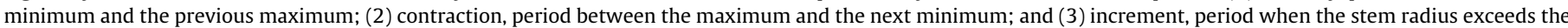
previous maximum until the subsequent maximum. Circles represent hourly data measured in July 2010.

issue, tests were validated using the bootstrap procedure (Efron and Tibshirani, 1993). Regressions and correlations were repeatedly calculated by randomly re-sampling the original data set and estimating the confidence intervals of the distribution.
Bootstrapping was performed 10,000 times to improve the robustness of the results (e.g. correlation coefficient or regression slope), which were considered significant when both confidence intervals were either higher or lower than zero.

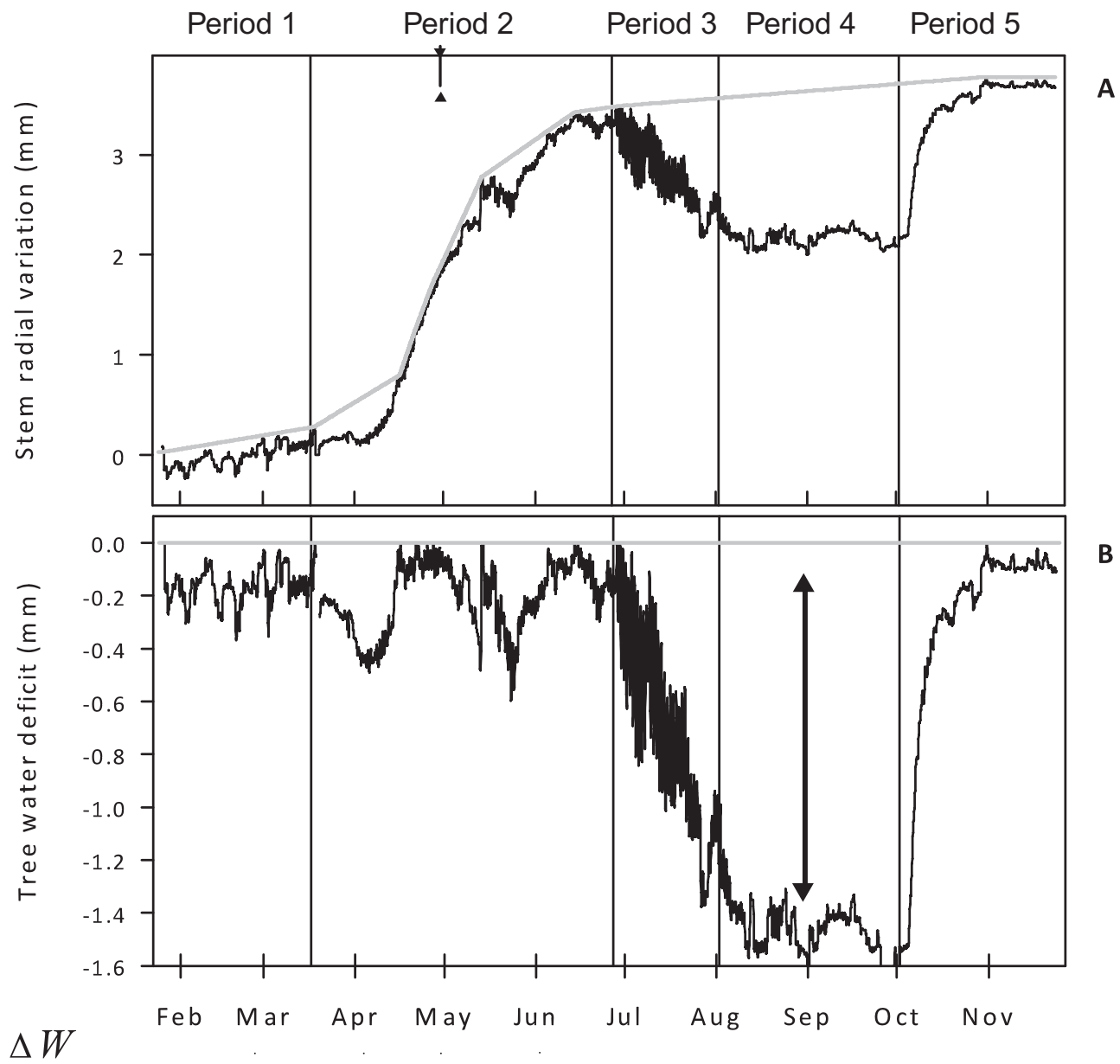

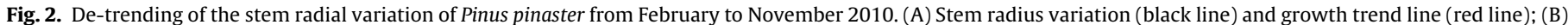

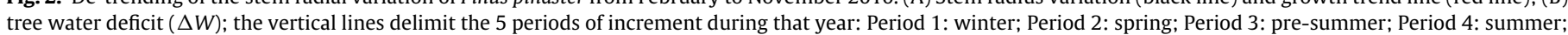
Period 5: autumn. (For interpretation of the references to colour in this figure legend, the reader is referred to the web version of this article.) 


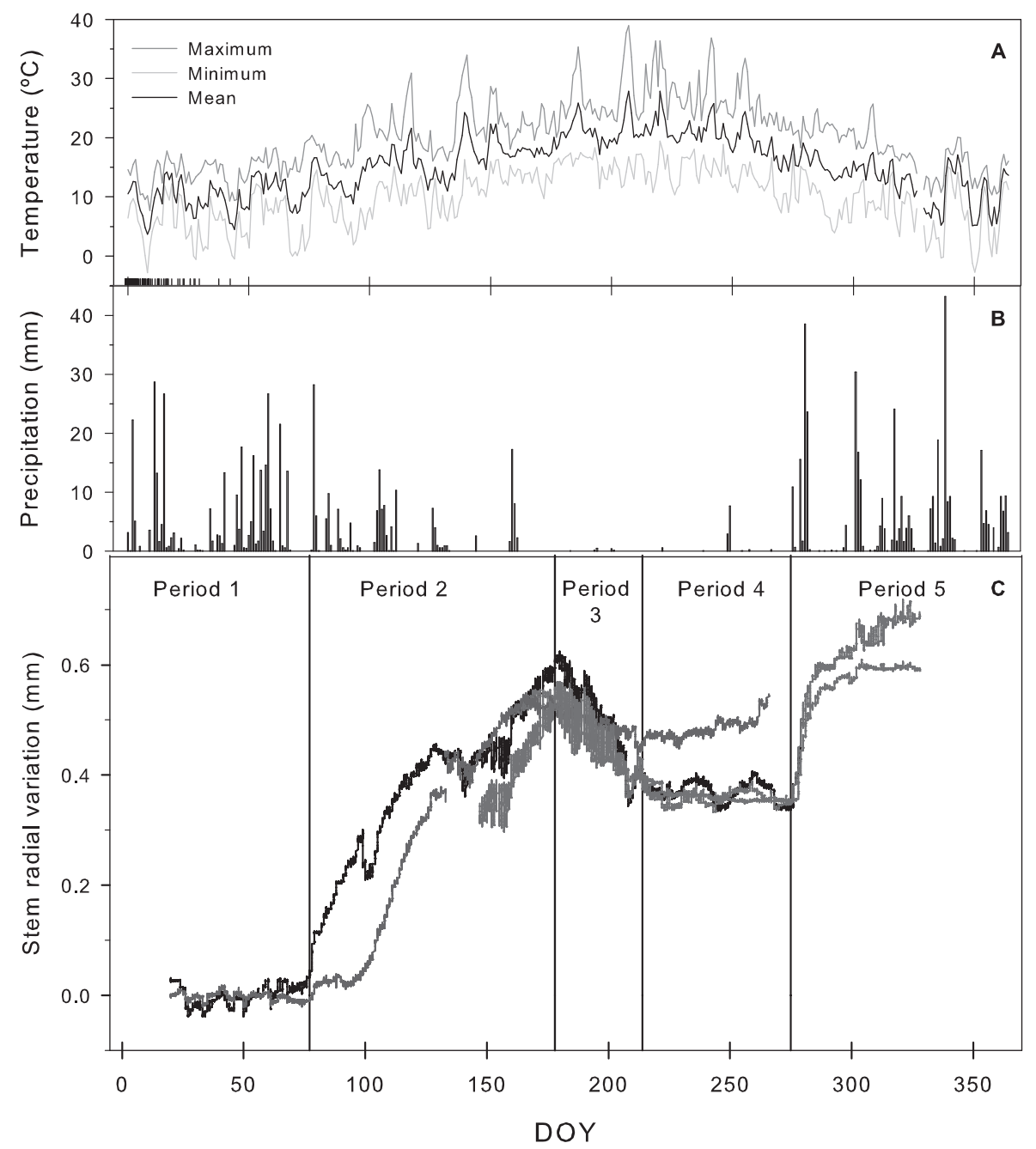

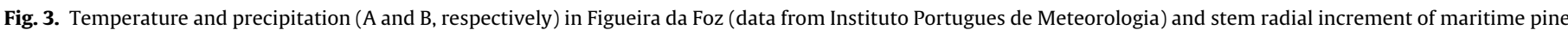

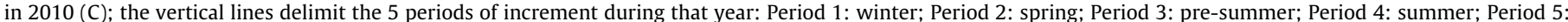

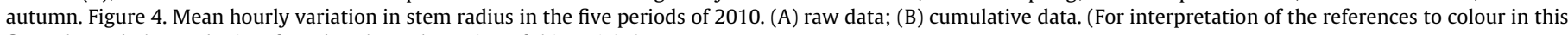
figure legend, the reader is referred to the web version of this article.)

\section{Results}

\subsection{Temperature and precipitation in 2010}

Mean daily temperature in the winter prior to the growing season ranged between 3 and $13^{\circ} \mathrm{C}$. The minimum temperature only dropped below $0^{\circ} \mathrm{C}$ on three occasions, on January 9 th and 29th, and February 14th (Fig. 3A). In spring and summer, temperatures rose reaching a maximum of $39^{\circ} \mathrm{C}$ in mid-July. In September, they started to gradually decrease, but mean temperatures were still above $15^{\circ} \mathrm{C}$. Temperatures only dropped below $10^{\circ} \mathrm{C}$ in midNovember. Precipitation was more frequent in January-March and October-November (Fig. 3B). In April precipitation started to decrease and very few precipitation events were observed from June to September, with a total of $40 \mathrm{~mm}$ registered during those months. The first precipitation in autumn occurred at the beginning of October, with a total of $90 \mathrm{~mm}$ in one week.

\subsection{Stem radial variation and tree water deficit}

Stem radius variation presented a clear seasonal pattern with marked characteristics in each period (Fig. 3C). Period 1 showed daily cycles of stem radius but no positive increment. Continuous positive radial increments were first observed in period 2 .
Vigorous growth was observed during this period, which lasted until the end of June, when a maximum was reached. In period 3, stem radius decreased markedly until the beginning of August. In August and September (period 4) the stem radial variation was minimal. In October (period 5), stem radius increased drastically within 10 days, which coincided with the first significant precipitation after the summer drought (Fig. 3B). Stem radial variation started to stabilize in November.

The variation observed in the tree water deficit was the opposite of that observed in stem radius (Fig. 2). In periods 1 and 2 the trees recovered during the night from the $\Delta W$ generated during the day (returning to zero). During period 3 there was a general decline of $\Delta W$ with trees not able to recover to a $\Delta W$ close to zero on a daily and monthly basis, resulting in the shrinkage of the stem. The $\Delta W$ remained negative during period 4 (summer). The stem only recovered the initial hydration status in period 5 .

Besides the seasonal pattern, stem radius variation changed considerably during a 24-h period (Figs. 1 and 4). The average maximum radius was observed between 09:00 and 13:00 and the minimum between 19:00 and 21:00 (Fig. 4A). The largest daily stem radius variation was observed in period 3 , with variations of up to $0.4 \mathrm{~mm}$. Although there was a circadian rhythm of contraction and recovery during period 1 , the cycles started and ended at the same radial value, suggesting that no increment occurred (Fig. 4B). 


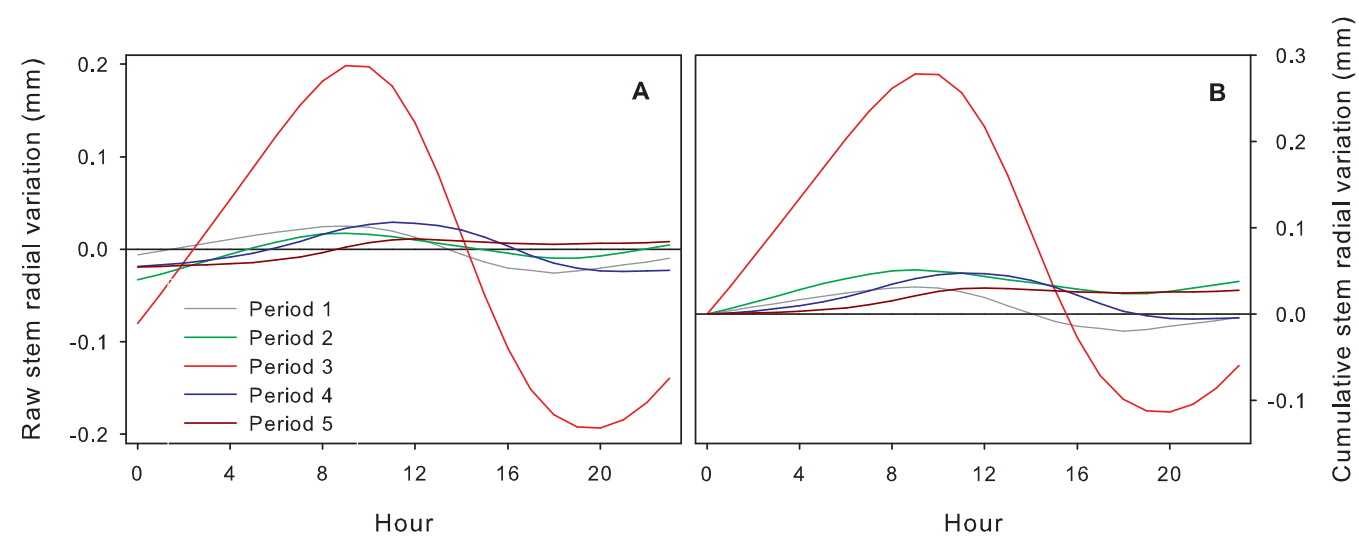

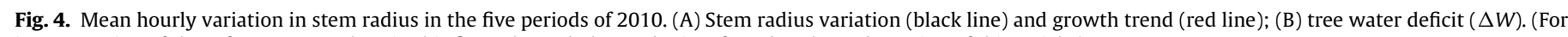
interpretation of the references to colour in this figure legend, the reader is referred to the web version of this article.)

In fact, continuous positive radial increments were only observed in period 2 and 5 (Fig. 4B). On the contrary, in periods 3 and 4 , the mean values at the end of the day were lower. The percentage of days with positive increment was also different in each period with periods 2, 5 and 1 presenting the higher percentage (71, 60 and $52 \%$, respectively) and periods 3 and 4 the lowest (33 and 44\%, respectively).

\subsection{Seasonal changes in cycle duration and amplitude}

The cycles presented different amplitudes and duration of their phases within every period (Fig. 5). Contraction and recovery phases varied between 0 and $0.6 \mathrm{~mm}$ and the increment ranged between -0.13 and $0.1 \mathrm{~mm}$. Period 3 showed the highest amplitude of contraction and recovery whereas the opposite was observed in period 5. Except for periods 1 and 5, recovery lasted longer than contraction. Increment was generally positive in periods 2 and 5 , negative in period 3 , while varying around zero in the remaining periods. The duration of increment decreased from period 1 and reached a minimum in period 3 , increasing again in periods 4 and 5.

Regression analyses revealed some significant linear relationships between amplitude and duration of the phases (Fig. 6). In period 3, the amplitude of recovery and increment was highly dependent on duration, and the same was observed in periods 4 and 5 for contraction. The distribution of the duration of phases was similar in periods 1 and 5 (Fig. 6, pie charts). In periods 2 and 3 , contraction had a longer duration than recovery and increment represented only $26 \%$ and $12 \%$ of the cycle, respectively. In period 4 the recovery lasted longer than the contraction phase.

\subsection{Responses to weather}

The amplitude and duration of stem radial variation presented different responses to temperature and precipitation throughout the year (Fig. 7). During period 1 (winter dormancy), a positive correlation was observed between maximum temperature and the amplitude of contraction and amplitude and duration of recovery. Period 2 (spring growth) showed similar results although a negative correlation with precipitation was also observed. Period 3 (presummer contraction) exhibited a positive response of amplitude of contraction and recovery to minimum temperature and a negative response of amplitude of contraction to maximum temperature. A negative response to minimum temperature was also observed in the duration of contraction. During the pre-summer contraction duration of increment also responded negatively to precipitation. In period 4 (summer) amplitude of contraction and recovery was positively correlated with minimum and maximum temperatures, respectively. A positive response was also observed between duration of contraction and recovery and maximum temperature. In period 5 (autumn), increment showed a positive correlation with minimum temperature.

\section{Discussion}

\subsection{Seasonal variation of stem radius and tree water deficit over the year}

The study investigated stem radius variations of maritime pine growing under a Mediterranean climate by identifying five periods of distinct physiological activity: winter dormancy, spring growth, pre-summer contraction, summer quiescence and autumn re-hydration. Radial increment started in spring and reached its maximum in June. A marked contraction was observed in summer, followed by a period of stable fluctuations. In autumn, after the first rains, the stem re-hydrated rapidly. At daily resolution, the cycles of radial variation changed in amplitude and duration during the year, with the largest variations exhibited in summer, when the amplitudes were 10 times higher than those observed in the other periods.

In trees of cold environments, stems show a marked rehydration before the beginning of growth (Deslauriers et al., 2003; Tardif et al., 2001; Turcotte et al., 2009), but this was not observed in maritime pine at the study site. Re-hydration is a direct consequence of the freezing temperatures: at high altitudes and latitudes, stem size closely follows the daily changes in winter temperature rather than the tree evapotranspiration, with shrinking and swelling occurring during the night and day, respectively, producing what is called an inverted cycle (Zweifel and Hasler, 2000). Ultimately, water is withdrawn from the living cells to avoid freezeinduced cavitation and, consequently, the stem diameter reduces (Zweifel and Hasler, 2000). Prior to spring growth, when temperatures rise above freezing point, the ice melts and water can replenish the living tissues (Turcotte et al., 2009). This swelling of the tissues restores the tree to a physiologically active state. In our study site however, there were no inverted cycles in winter indicating that the sap did not reach freezing point. In fact, temperatures only dropped below $0^{\circ} \mathrm{C}$ occasionally and for short periods.

Marked stem contractions and re-hydrations were observed in summer and autumn, respectively. In July, when the highest temperatures and day length were registered in the site, the circadian cycles of stem contraction and recovery showed amplitudes 10 times higher than in the rest of the year. A similar finding was made by King et al. (2012) in the Swiss Alps. They observed that 

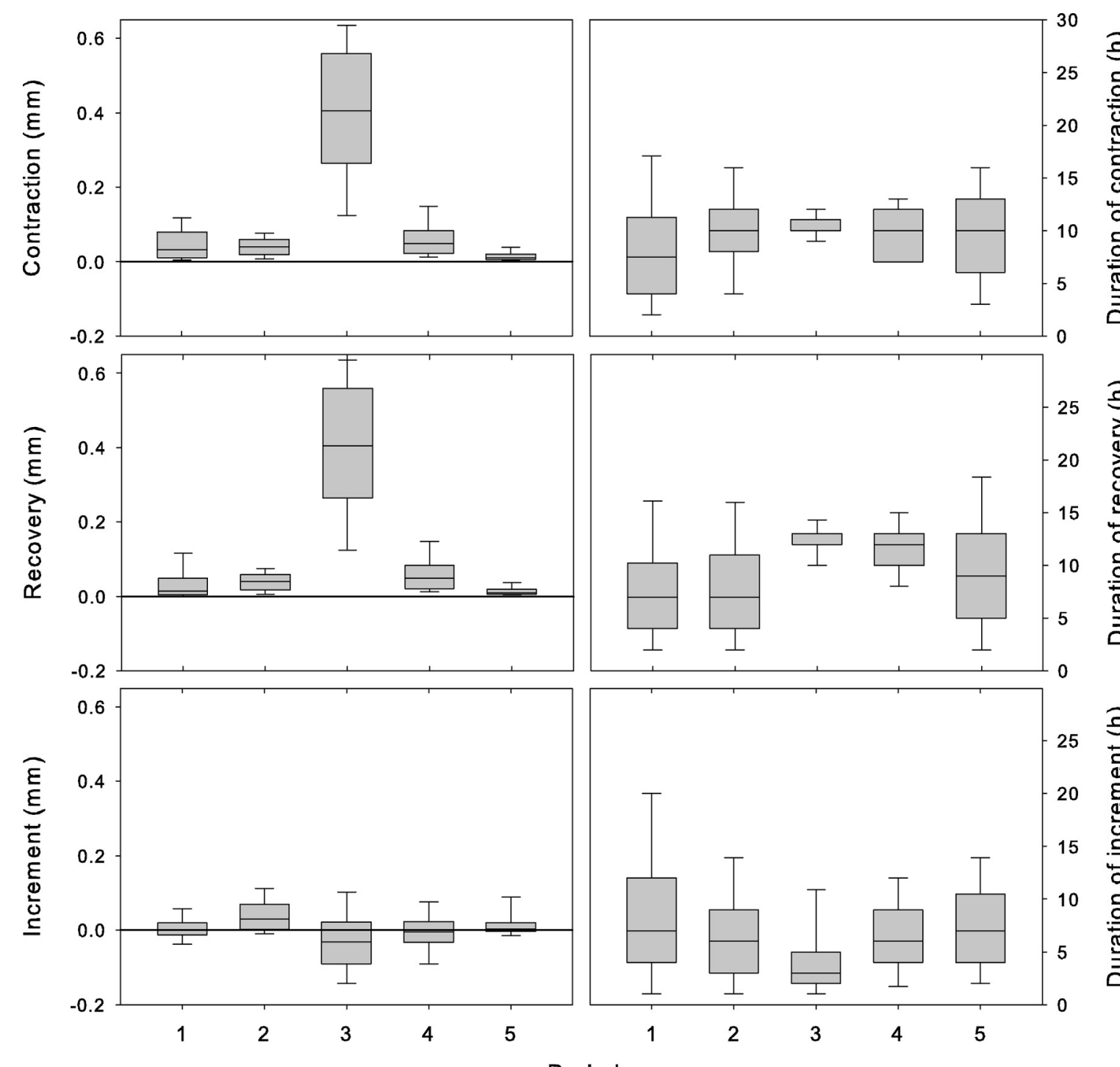

Periods

Fig. 5. Amplitude and duration of the three phases of stem radius variation.

a rise of $10^{\circ} \mathrm{C}$ in temperature increased the stem cycle amplitude of spruce and larch of $40 \%$. Increased temperatures and day length combined, reduced the duration of the recovery phase (as seen in Fig. 6) and increased the water lost by transpiration (Cermak et al., 2007). During the summer, the recovery phase was not sufficient to replenish the stem from the water lost during the day and trees had to resorted to the internal water storage to keep up the transpiration demands (De Schepper and Steppe, 2010; Sevanto et al., 2002; Zweifel et al., 2001).

The stem shrinkage observed during July (period 3) corresponded to the period when the $\Delta W$ presented a clear decreasing trend which can be associated with the exhaustion of the internal water storage. In the summer, soil water content diminishes and day length increases which decreases recovery. Ultimately the transpiration demands are not meet and the stem gradually contracts from one cycle to the next (Devine and Harrington, 2011). Transpiration is controlled by stomatal responses to water availability (Jarvis and McNaughton, 1986; Zweifel et al., 2006). To avoid drought-induced hydraulic failure, stomata closes during midday to maintain a water potential above the threshold of xylem cavitation (Loustau et al., 1996). The physiological consequences of stomata closure are carbon starvation and secondary growth decline, due to the allocation of carbon to higher ranking physiological processes such as root growth (Chaves et al., 2002; Oribe et al., 2003; Zweifel et al., 2006). As a result, trees reduce their metabolism and enter in quiescence (Cherubini et al., 2003; McDowell et al., 2008). In autumn, a period of re-hydration was observed in response to precipitation events. During the first 10 days of period 5 , a series of cycles lasting more than $24 \mathrm{~h}$ (long cycles) were observed, corresponding to a vigorous re-hydration.

The relationship between duration and amplitude of the stem radial variation phases changed during the year and reflected the prevailing climatic factors in each period. During period 3 the amplitude of recovery and increment was highly dependent on its duration. The recovery phase takes place mostly during the night. In the summer the days are longer which restricts the duration of recovery. If the duration of recovery is not sufficient to replenish the stem, then recovery will be limited and positive increments would not occur at all. As a consequence, the stem would progressively contract, which explains the negative increments observed during this period.

During period 4 (summer), when tree water deficit was higher, a positive correlation was observed between the duration and amplitude of contraction. This relation is directly connected to the overall 


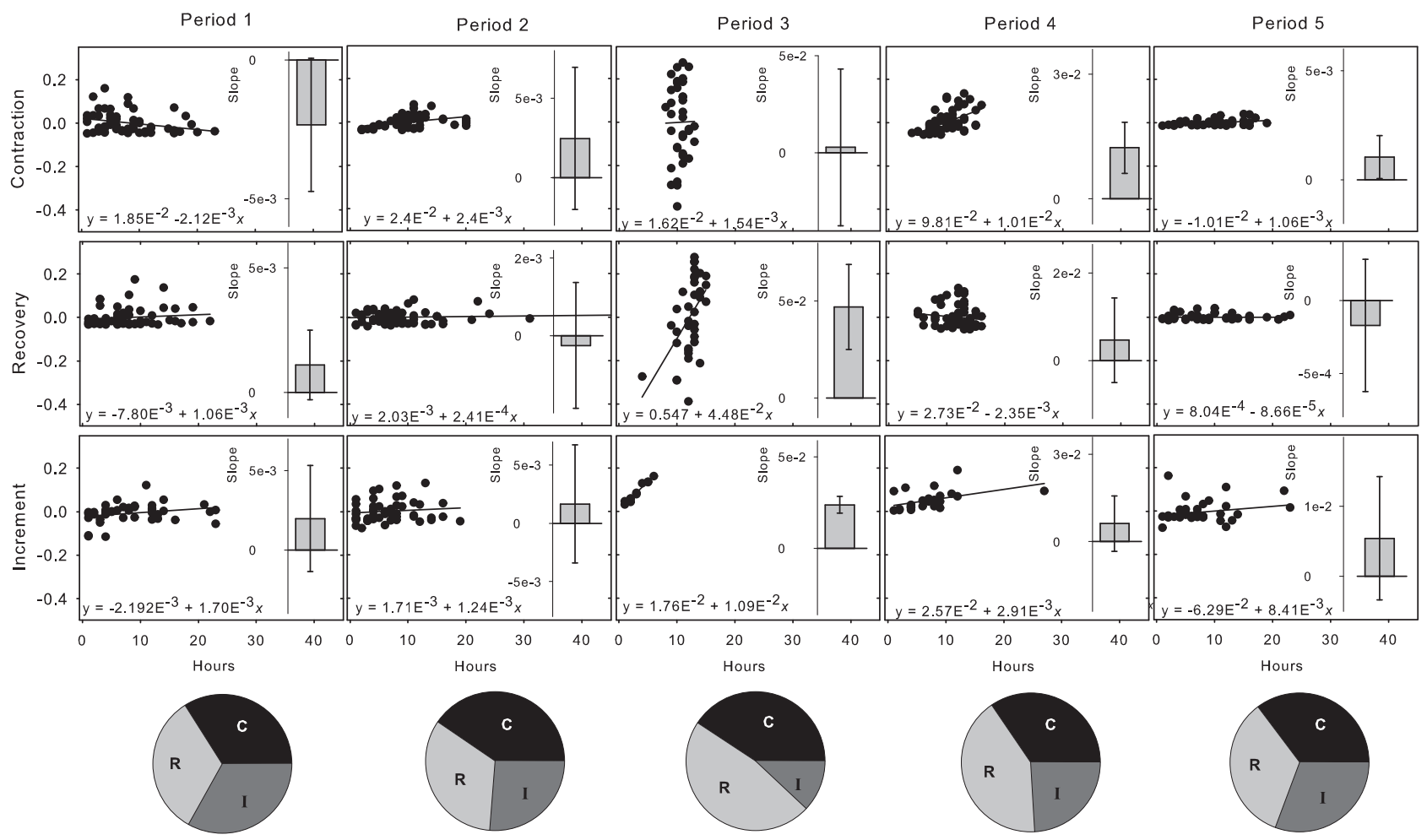

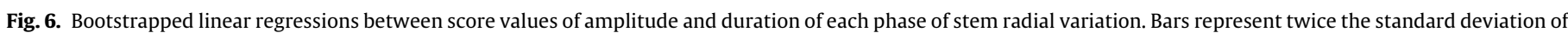

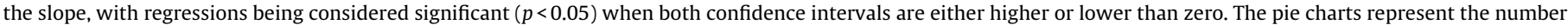
of hours of contraction, expansion and increment per period.

tree water status. During the summer the tree could not compensate for the water daily losses, presenting the most negative $\Delta W$ values. If the tree can no longer replenish the water lost by transpiration, then contraction would have to be restrained, which would result in a higher dependence between duration and amplitude. The opposite relationship was observed in periods 1 and 2, when the recovery phase was not limited, and the same amplitudes of contraction and recovery were achieved independently of duration. In autumn, the soil was replenished with water, thus amplitude and duration of recovery and increment were no longer dependent. However, due to the short duration of contraction during this period, a consequence of the long cycles, contraction amplitude was dependent on its duration.

\subsection{Climatic response}

The climatic response of duration was less clear than that of amplitude. During the first period, maximum temperature presented a positive correlation with recovery and contraction amplitudes and recovery duration, but no significant correlation with minimum temperature was observed. It is a well-documented fact that temperature can limit growth onset (Deslauriers et al., 2008; Rossi et al., 2007, 2008). Rossi et al. (2008) determined that the average minimum temperature for xylogenesis was $4-5^{\circ} \mathrm{C}$. In our study site, the average minimum temperature in winter was $6^{\circ} \mathrm{C}$, which suggests that in the Mediterranean region, the minimum temperatures limiting cambial onset are higher. Several studies in the Mediterranean region have documented an earlier onset of cambial activity in response to higher winter temperatures (Camarero et al., 2010; de Luis et al., 2007; Linares et al., 2009). However, no threshold temperature has been yet determined for this area. The positive correlations observed in period 1 are indicative that trees were physiologically active during the winter. Corcuera et al. (2011) observed that, as in other
Mediterranean evergreen conifers, maritime pine can maintain physiological activity all year round. It has also been demonstrated that cambial activity can be maintained during mild winters (Cherubini et al., 2003; Liphschitz and Levyadun, 1986). In fact, maritime pine in the study area presented a long-lasting xylem differentiation persisting until December (Vieira et al., unpublished results).

In period 2 the climatic conditions were optimal for tree growth with most of the increment being observed during this period. Previous dendrochronological studies on maritime pine showed that the climatic conditions observed in spring were the most determinant for tree-ring width (Campelo et al., 2013; Vieira et al., 2009). The climatic response of contraction and recovery was similar in this period, which, once again, demonstrates the interdependency of the two phases. The positive correlation found between contraction and maximum temperature suggests that transpiration rates were elevated. As temperature rises, transpiration rates increase, promoting water loss and contraction (Cermak et al., 2007; Zweifel et al., 2001). Contraction and recovery also showed a negative correlation with precipitation in period 2 . Studies on the diurnal course of transpiration showed that even irrigated trees experience stomatal closure if root water uptake is not sufficient to keep up with transpiration (White et al., 1996). The negative response of contraction to precipitation can be due to the indirect effect of clouds. Clouds would decrease direct solar radiance, thus decreasing leaf temperature, transpiration and ultimately contraction (King et al., 2012).

In July (period 3), the amplitude of contraction showed a negative correlation with maximum temperature. During this period, temperatures are high and soil water content is lower, thus stomatal control on transpiration rates is stronger (Jarvis and McNaughton, 1986; Zweifel et al., 2006). The stronger control of transpiration has a negative effect on contraction, reducing it. A positive correlation between amplitude of recovery and 


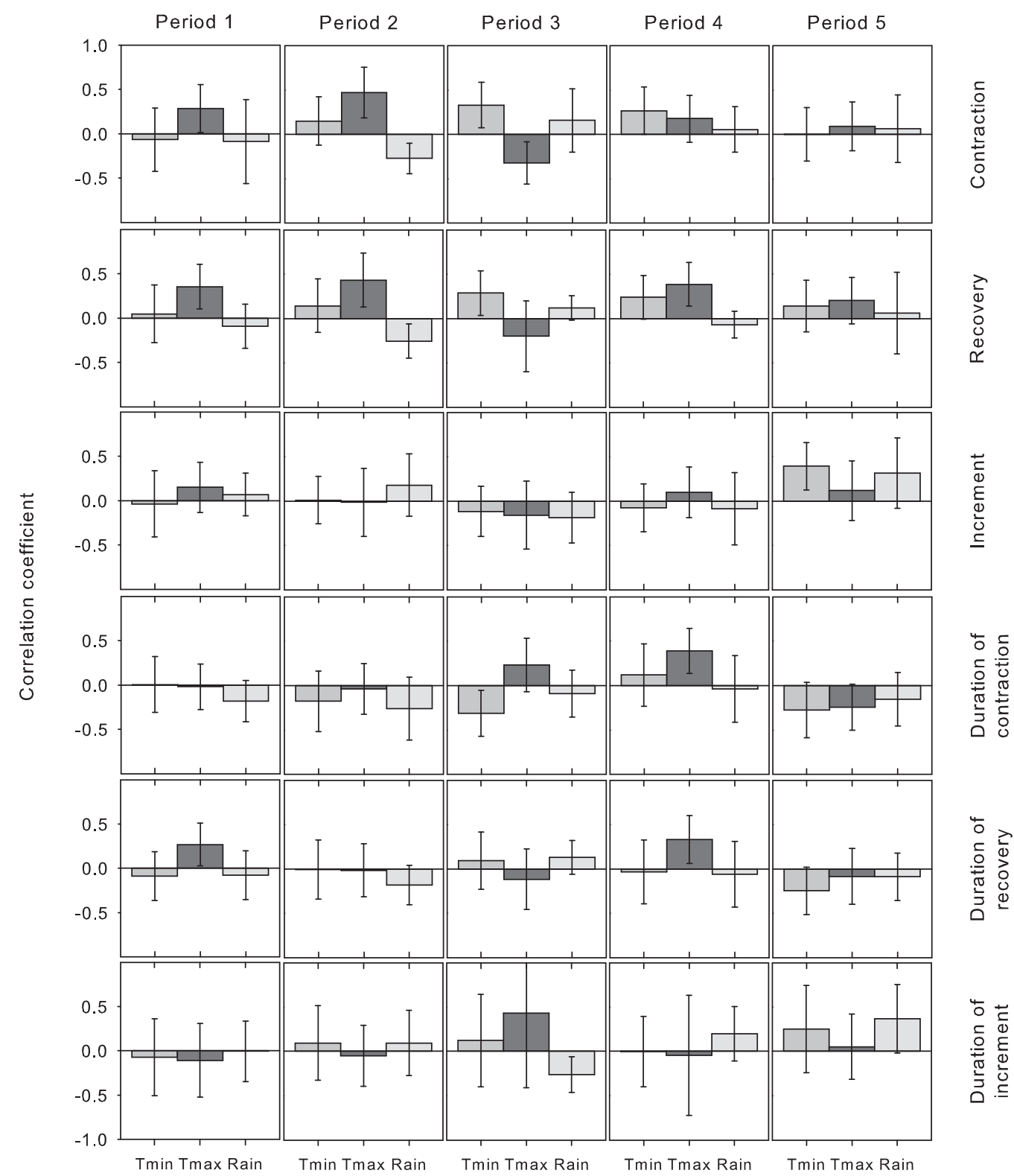

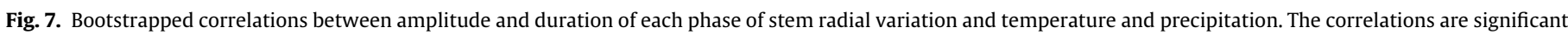
$(p<0.05)$ when the confidence interval (twice the standard deviation, drawn as vertical error bar) is either higher or lower than zero.

contraction and minimum temperature was also observed during this period. Lower temperatures benefit recovery, which translates in a better overnight hydration allowing a bigger contraction the following day.

In autumn (period 5), a positive correlation was observed between increment and minimum temperature. During this period there is a general decrease of temperature and photoperiod, which will induce a decrease in physiological activity, with the minimum temperature establishing the threshold for stem radius variation. Contraction did not show any correlation with the climatic parameters, revealing that expansion is a far more prominent phase during this period, as a consequence of the long cycles. Although stem rehydration was observed during this period, no positive correlations with precipitation were registered. The re-hydration period, which corresponded to the long cycles, only lasted for 10 days whereas the rest of period 5 corresponded to the stabilization of stem size variation, and this may be the reason why the correlations were not significant.

\section{Conclusions}

The investigation confirmed our hypothesis that maritime pine stem radius variation has a daily and seasonal pattern that reflects the availability of water. Daily variations in stem radius were mainly determined by the course of transpiration and thus dependent on temperature and tree water status. The balance between water loss via transpiration and water uptake by the roots demonstrated a strong dependence between contraction and recovery phases. Ultimately the rate of root water uptake and soil water content limited stem radius variation and the trees entered in a quiescent state, confirming our second hypothesis.

Temperature played an important part in stem size variation during the year, both directly by increased transpiration, and indirectly by decreasing soil water content via evapotranspiration. The increment onset of maritime pine was dependent on maximum temperature rather than minimum temperature, as observed on trees in cold environments. Nonetheless, water availability played 
the major role in stem radial variations. The severe water stress observed in summer caused the stem to contract and the tree to enter a quiescent period, confirming the importance of water regulation in the survival of trees in a drought prone environment, such as the Mediterranean.

\section{Acknowledgments}

The authors would like to thank Eng. José Louzada, for loaning us the automatic dendrometers and A. Garside for checking the English. The authors would also like to thank the two anonymous reviewers for their comments. This study was supported by the Fundação para a Ciência e a Tecnologia, Ministério da Educação e Ciência (FCT) co-financed by Compete, through the project PTDC/AAC-AMB/111675/2009. J. Vieira was supported by a Ph.D. grant (SFRH/BD/48089/2008) from FCT with funds from POPH (Portuguese Operational Human Potential Program) and QREN Portugal (Portuguese National Strategic Reference Framework).

\section{References}

Camarero, J.J., Olano, J.M., Parras, A., 2010. Plastic bimodal xylogenesis in conifers from continental Mediterranean climates. New Phytol. 185 (2), 471-480.

Campelo, F., Vieira, J., Nabais, C., 2013. Tree-ring growth and intra-annual density fluctuations of Pinus pinaster responses to climate: does size matter? Trees 27 (3), 763-772.

Cermak, J., Kucera, J., Bauerle, W.L., Phillips, N., Hinckley, T.M., 2007. Tree water storage and its diurnal dynamics related to sap flow and changes in stem volume in old-growth Douglas-fir trees. Tree Physiol. 27 (2), 181-198.

Chaves, M.M., et al., 2002. How plants cope with water stress in the field. Photosynthesis and growth. Ann. Bot. 89, 907-916.

Cherubini, P., Gartner, B.L., Tognetti, R., Braker, O.U., Schoch, W., Innes, J.L., 2003. Identification, measurement and interpretation of tree rings in woody species from mediterranean climates. Biol. Rev. 78 (1), 119-148.

Corcuera, L., Gil-Pelegrin, E., Notivol, E., 2011. Intraspecific variation in Pinus pinaster PSII photochemical efficiency in response to winter stress and freezing temperatures. PLOS ONE 6 (12).

CRU, 2011. Netherlands Royal Meteorological Institute CRU TS 3.1. http://climexp.knmi.nl/

de Luis, M., Gricar, J., Cufar, K., Raventos, J., 2007. Seasonal dynamics of wood formation in Pinus halepensis from dry and semi-arid ecosystems in Spain. IAWA J. 28 (4), 389-404.

De Schepper, V., Steppe, K., 2010. Development and verification of a water and sugar transport model using measured stem diameter variations. J. Exp. Bot. 61 (8), 2083-2099.

Deslauriers, A., Morin, H., Urbinati, C., Carrer, M., 2003. Daily weather response of balsam fir (Abies balsamea (L.) Mill.) stem radius increment from dendrometer analysis in the boreal forests of Quebec (Canada). Trees 17 (6), 477-484.

Deslauriers, A., Anfodillo, T., Rossi, S., Carraro, V., 2007. Using simple causal modeling to understand how water and temperature affect daily stem radial variation in trees. Tree Physiol. 27 (8), 1125-1136.

Deslauriers, A., Rossi, S., Anfodillo, T., Saracino, A., 2008. Cambial phenology, wood formation and temperature thresholds in two contrasting years at high altitude in southern Italy. Tree Physiol. 28 (6), 863-871.

Deslauriers, A., Rossi, S., Turcotte, A., Morin, H., Krause, C., 2011. A three-step procedure in SAS to analyze the time series from automatic dendrometers. Dendrochronologia 29 (3), 151-161.

Devine, W.D., Harrington, C.A., 2011. Factors affecting diurnal stem contraction in young Douglas-fir. Agric. Forest Meteorol. 151 (3), 414-419.

Downes, G., Beadle, C., Worledge, D., 1999. Daily stem growth patterns in irrigated Eucalyptus globulus and E. nitens in relation to climate. Trees 14 (2), $102-111$.
Drew, D.M., Richards, A.E., Downes, G.M., Cook, G.D., Baker, P., 2011. The development of seasonal tree water deficit in Callitris intratropica. Tree Physiol. 31 (9), 953-964.

Duchesne, L., Houle, D., 2011. Modelling day-to-day stem diameter variation and annual growth of balsam fir (Abies balsamea (L.) Mill.) from daily climate. For. Ecol. Manage. 262 (5), 863-872.

Efron, B., Tibshirani, R.J., 1993. An Introduction to the Bootstrap. Chapman \& Hall, London, $436 \mathrm{p}$.

Gutierrez, E., Campelo, F., Camarero, J., Ribas, M., Muntan, E., Nabais, C., Freitas, H., 2011. Climate controls act at different scales on the seasonal pattern of Quercus ilex L. stem radial increments in NE Spain. Trees 25 (4), 637-646.

Irvine, J., Grace, J., 1997. Continuous measurements of water tensions in the xylem of trees based on the elastic properties of wood. Planta 202 (4), 455-461.

Jarvis, P.G., McNaughton, K.G., 1986. Stomatal control of transpiration-scaling up from leaf to region. Adv. Ecol. Res. 15, 1-49.

King, G., Fonti, P., Nievergelt, D., Buntgen, U., Frank, D., 2012. Climatic drivers of hourly to yearly tree radius variations along a $6^{\circ} \mathrm{C}$ natural warming gradient. Agr. For. Meteorol. 168, 36-46.

Kozlowski, T.T., 1976. Shrinking and swelling of plant tissues. In: Kozlowski, T.T. (Ed.), Water Deficits and Plant Growth. Academic Press, New York, pp. 1-64.

Linares, J.C., Camarero, J.J., Carreira, J.A., 2009. Plastic responses of Abies pinsapo xylogenesis to drought and competition. Tree Physiol. 29 (12), 1525-1536.

Liphschitz, N., Levyadun, S., 1986. Cambial activity of evergreen and seasonal dimorphics around the Mediterranean. IAWA Bull. 7 (2), 145-153.

Loustau, D., Berbigier, P., Roumagnac, P., ArrudaPacheco, C., David, J.S., Ferreira, M.I., Pereira, J.S., Tavares, R., 1996. Transpiration of a 64-year-old maritime pine stand in Portugal. 1. Seasonal course of water flux through maritime pine. Oecologia 107 (1), 33-42.

McDowell, N., Pockman, W.T., Allen, C.D., Breshears, D.D., Cobb, N., Kolb, T., Plaut, J., Sperry, J., West, A., Williams, D.G., Yepez, E.A., 2008. Mechanisms of plant survival and mortality during drought: why do some plants survive while others succumb to drought? New Phytol. 178 (4), 719-739.

Oribe, Y., Funada, R., Kubo, T., 2003. Relationships between cambial activity, cell differentiation and the localization of starch in storage tissues around the cambium in locally heated stems of Abies sachalinensis (Schmidt) Masters. Trees 17 (3), 185-192.

Peramaki, M., Vesala, T., Nikinmaa, E., 2005. Modeling the dynamics of pressure propagation and diameter variation in tree sapwood. Tree Physiol. 25 (9), 1091-1099.

Rossi, S., Deslauriers, A., Anfodillo, T., Carraro, V., 2007. Evidence of threshold temperatures for xylogenesis in conifers at high altitudes. Oecologia 152 (1), 1-12.

Rossi, S., Deslauriers, A., Gricar, J., Seo, J.W., Rathgeber, C.B.K., Anfodillo, T., Morin, H., Levanic, T., Oven, P., Jalkanen, R., 2008. Critical temperatures for xylogenesis in conifers of cold climates. Global Ecol. Biogeogr. 17 (6), 696-707.

Sevanto, S., Vesala, T., Peramaki, M., Nikinmaa, E., 2002. Time lags for xylem and stem diameter variations in a Scots pine tree. Plant Cell Environ. 25 (8), 1071-1077.

Tardif, J., Flannigan, M., Bergeron, Y., 2001. An analysis of the daily radial activity of 7 boreal tree species, northwestern Quebec. Eviron. Monit. Assess. 67 (1-2), $141-160$.

Turcotte, A., Morin, H., Krause, C., Deslauriers, A., Thibeault-Martel, M., 2009. The timing of spring rehydration and its relation with the onset of wood formation in black spruce. Agric. For. Meteorol. 149 (9), 1403-1409.

Vieira, J., Campelo, F., Nabais, C., 2009. Age-dependent responses of tree-ring growth and intra-annual density fluctuations of Pinus pinaster to Mediterranean climate. Trees 23 (2), 257-265.

White, D.A., Beadle, C.L., Worledge, D., 1996. Leaf water relations of Eucalyptus globulus ssp globulus and E. nitens: seasonal, drought and species effects. Tree Physiol. $16(5), 469-476$.

Zweifel, R., Hasler, R., 2000. Frost-induced reversible shrinkage of bark of mature subalpine conifers. Agric. For. Meteorol. 102 (4), 213-222.

Zweifel, R., Item, H., Hasler, R., 2000. Stem radius changes and their relation to stored water in stems of young Norway spruce trees. Trees 15 (1), 50-57.

Zweifel, R., Item, H., Hasler, R., 2001. Link between diurnal stem radius changes and tree water relations. Tree Physiol. 21 (12-13), 869-877.

Zweifel, R., Zimmermann, L., Newbery, D.M., 2005. Modeling tree water deficit from microclimate: an approach to quantifying drought stress. Tree Physiol. 25 (2), $147-156$.

Zweifel, R., Zimmermann, L., Zeugin, F., Newbery, D.M., 2006. Intra-annual radial growth and water relations of trees: implications towards a growth mechanism. J. Exp. Bot. 57 (6), 1445-1459. 